\title{
The influence of hearing loss on transport safety and mobility
}

\author{
Birgitta Thorslund • Björn Peters • Björn Lyxell • \\ Björn Lidestam
}

Received: 31 May 2012 / Accepted: 13 November 2012 /Published online: 30 November 2012

(C) The Author(s) 2012. This article is published with open access at SpringerLink.com

\begin{abstract}
Purpose To examine how road users with different degree of hearing loss experience safety and mobility in transport situations, compared to road users with normal hearing.

Methods A questionnaire study was conducted with participants recruited from the local branch of The Swedish hard of hearing society. A normal hearing control group, matched on age, gender and geographical location, was selected from a commercial database. The response rate was $35 \%(n=$ 194) in the group with Hearing Loss (HL) and $42 \%(n=$ 125 ) in the group with Normal Hearing (NH). The individuals with hearing loss were grouped into four groups according to the degree of their hearing loss (mild, moderate, severe and profound).

Results Hearing loss affected some specific aspects regarding transport situations, while others remained unaffected. Individuals with hearing loss were not as likely to have a driving license, but for those who have, hearing loss had no effect on mileage per year. Loss of hearing had an effect on criteria for choosing mode of transportation, but in the aggregate, no difference between the groups could be shown in the distribution of how much each mode of transportation was used. With a few exceptions, hearing loss did not affect the ratings of importance of hearing for different transportation modes. Hearing loss affected most questions regarding hearing and driver abilities, while avoidance of specific traffic situations was not associated with hearing loss. Hearing loss had only minor effects on the factors causing inattention when driving,
\end{abstract}

B. Thorslund $(\square) \cdot B$. Peters

VTI (Swedish National Road and Transport Research Institute),

Linköping, Sweden

e-mail: birgitta.thorslund@vti.se

B. Thorslund $\cdot$ B. Peters $\cdot$ B. Lyxell $\cdot$ B. Lidestam

Linnaeus Centre HEAD, Linköping University,

Linköping, Sweden and on the interest in a warning system for driver inattention. The interest in a warning system for driver inattention was high regardless of hearing category.

Conclusions Hearing loss influences the prevalence of driving license and criteria for choosing mode of transportation, however has no effect on the distribution of how much each mode of transportation was used. In general, in this study, respondents with higher degree of hearing loss were less concerned about the effect of hearing loss, indicating that they might be using coping strategies. The interest in warning system for inattention and the attitude towards strengthening of auditory information in traffic situations is high regardless of hearing category. This suggests further research on coping strategies and on design of support systems accessible for drivers with hearing loss.

Keywords Hearing loss · Transportation · Safety · Mobility $\cdot$ Support system

\section{Introduction}

A consequence of hearing loss is loss of auditory information and this loss may affect behavior in traffic situations and can reduce traffic safety. Schmolz [12] revealed the importance of hearing capability for road users and that higher degree of inattention is often due to reduced hearing. Lundälv [10] stated that adult pedestrians and cyclists with moderate hearing loss are at a higher risk of being injured by a vehicle, because they find it difficult to identify in which direction sounds are coming from. According to The Swedish hard of hearing society (Hörselskadades riksförbund, HRF), there are approximately 1.3 million adults in Sweden (17\%) with a hearing loss [8]. This number is increasing, due to both longer life and more noise in the environments. The prevalence increases for all ages, although the most common category of hearing loss is presbycusis, which is related to age 
[8]. The older part of the population is increasing and the number of road users with hearing loss will thus also increase.

The field of transportation and hearing loss has received relatively little attention in the literature and the level of knowledge is thus rather low. Hearing loss is not an impediment for obtaining a driving license for passenger cars, since individuals with hearing loss are not considered as an increased traffic safety risk [4]. However, Hickson and coworkers [5] showed that hearing loss in older drivers is associated with poorer driving performance in the presence of visual or auditory sources of distraction.

Having a driving license is more common for men than for women among older adults today [3]. Several studies [3, $9,11]$ have revealed that among older couples, even if both have a driving license, the man is typically more often the driver. A cohort study among the next generation of older adults (from 65 years), showed an increase of daily trips in all transportation modes for both men and women, and it is expected that this population will be more mobile at the age of 80-90 than those of this age are today [7].

The use of innovative driver support systems in vehicles (e.g., collision warning, parking aid, and lane keeping systems) is increasing rapidly and the systems are becoming more and more advanced. Due to a more complex in-vehicle environment (e.g., navigation system, mobile phone), there is an increased risk of distracting the driver from the driving task. Existing driver support systems frequently utilize auditory information and may to some extent exclude drivers with hearing loss. Thus, due to the low level of knowledge in the field of hearing and transport, there is a need to describe the population of road users with hearing loss and their limitations and needs with respect to safe mobility. This study is the first step of a project initiated at VTI regarding hearing loss, traffic safety and mobility and the purpose is to compare how individuals, with and without hearing loss, experience safety and mobility in transport situations.

If or when hearing loss is experienced as a problem or as restricting for the individual has to do with if loss of hearing results in a state of disability. This occurs in some particular situations and in some others not. Thus, in each situation, it is necessary to distinguish between different types of hearing loss to be able to understand the consequences and possible difficulties related to it. For example, some potential problems are associated with car drivers, (e.g. hearing warnings from your car). Other possible complications are associated with a specific group of individuals using sign language, (e.g. signing when driving). Areas of interest are for example communication, emergency situations, sound perception and vehicle signals.

Due to differences related to specific circumstances and situations (e.g. communication difficulties, lack of information) it is likely to believe that experiences and attitudes in transport situations vary between individuals with different degrees of hearing loss. In the present study, experiences and attitudes regarding safety and mobility among road users with and without hearing loss was examined.

In order to examine the effect of hearing loss on transportation habits and on the attitudes towards safety and mobility, the participants were categorized by the degree of their hearing loss and whether the loss was uni- or bilateral. Specifically, three general questions were examined: (a) how hearing loss affects the choice of transportation mode; (b) the personal view of hearing loss in relation to transport situations (e.g. car driving, bike riding, public transportation); and (c) the need and the design of support systems (e.g collision warning, parking aid, navigation systems, lane keeping systems) for road users with hearing loss.

\section{Method}

\subsection{Recruitment procedure}

An invitation to participate in the questionnaire study was sent out to all members over 25 years of age $(N=555)$ of the local branch of HRF (The Swedish hard of hearing society). This is the major organization in Sweden for individuals with hearing loss (32,000 members in total). The reason for the age limit was that the participants should have had time to decide whether to get a driving license and in that case acquire some driving experience, however the mean age in this group is rather high (Mean 71 years, SD 15 years). Furthermore, a hearing control group $(N=300)$, matched on age, gender and geographical location, was selected and also asked to answer the questionnaire. The selection was performed by the Swedish National Personal Directory (SPAR, Statens Personadressregister) by matching all background information into specific sample size.

\subsection{Participants}

The response rate was $35 \%(n=194)$ in the group with Hearing Loss (HL) and $42 \%(n=124)$ in the group with Normal Hearing (NH). Declines came from both groups ( $n=$ 39 for $\mathrm{HL}$ and $n=15$ for $\mathrm{NH}$ ), either personally or through a relative. This was either due to dementia, disability (keeping them from using the road) or lack of interest. Due to the fact that hearing disorder is quite common among older adults, it was expected that part of the respondents from the control group would be individuals with hearing loss who for some reason have not joined the hard of hearing society. The percentage of hearing loss in the control group was $25 \%$ $(n=31)$. All respondents with an audiogram available at the clinic were included in the HL - group, which increased to 218 and the NH - group decreased to 93 respondents. In the case respondents had answered that they have a hearing disorder, but no audiogram was available, these respondents were excluded from the analysis $(n=7)$. 
From audiogram data, participants were sorted into groups according to their degree of hearing loss. A Pure Tone Average of four air conduction thresholds, PTA4 (mean of 500, 1,000, 2,000 and 4,000 Hz), was calculated and five categories defined according to the WHO classification [14]: Normal Hearing $(<26 \mathrm{~dB})$, Mild Hearing Loss (26-40 dB), Moderate Hearing Loss (41-60 dB), Severe Hearing Loss (61-80 dB) and Profound Hearing Loss $(>80 \mathrm{~dB})$. Additionally, individuals with unilateral or bilateral hearing loss were separated for each category. Table 1 shows the distribution of the participants according to this procedure. The present study does not include participants who are deaf, also none of the participants used or were dependent of sign language for communication.

The majority of the participants were retired $(74 \% \mathrm{HL}$, $61 \% \mathrm{NH})$. The second largest group was employed or selfemployed (19\% HL, $38 \% \mathrm{NH})$.

\subsection{Materials and procedure}

A web based questionnaire was constructed to capture habits, experiences and attitudes in transport situations, see Appendix. The 20 questions were presented in three groups, and formulated with the aim to investigate the three research questions and thus covered (A) Background, Travel habits and Criteria for choice of transportation mode (Questions 1-10); (B) Hearing as an information source, Traffic situations that

Table 1 Distribution of participants due to type of hearing loss

\begin{tabular}{|c|c|c|c|c|}
\hline \multirow[t]{2}{*}{ Category $(n)$} & & \multirow[t]{2}{*}{ Gender $(n)$} & \multicolumn{2}{|c|}{$\begin{array}{l}\text { Age } \\
\text { (Years) }\end{array}$} \\
\hline & & & M & SD \\
\hline \multirow[t]{2}{*}{ NH (93) } & & $\mathrm{M}(50)$ & 71.5 & 13.2 \\
\hline & & W (43) & 63.4 & 14.5 \\
\hline \multirow[t]{4}{*}{ Mild hearing loss (48) } & UHL: Unilateral (9) & $M(7)$ & 72.1 & 8.0 \\
\hline & & W (2) & 42.0 & 18.3 \\
\hline & BHL Bilateral (39) & M (10) & 70.4 & 12.7 \\
\hline & & W (29) & 69.8 & 10.1 \\
\hline \multirow{4}{*}{$\begin{array}{l}\text { Moderate hearing } \\
\text { loss (105) }\end{array}$} & UHL Unilateral (20) & $M(7)$ & 71.3 & 9.7 \\
\hline & & W (13) & 63.2 & 11.2 \\
\hline & BHL Bilateral (85) & M (37) & 77.5 & 8.3 \\
\hline & & W (48) & 69.1 & 15.1 \\
\hline \multirow{4}{*}{$\begin{array}{l}\text { Severe hearing } \\
\text { loss }(47)\end{array}$} & UHL Unilateral (3) & M (2) & 43.5 & 0.7 \\
\hline & & W (1) & 33.0 & - \\
\hline & BHL Bilateral (44) & M (26) & 76.7 & 10.8 \\
\hline & & W (18) & 70.1 & 13.7 \\
\hline \multirow{4}{*}{$\begin{array}{l}\text { Profound hearing } \\
\text { loss (18) }\end{array}$} & UHL Unilateral (2) & $\mathrm{M}(0)$ & - & - \\
\hline & & W (2) & 67.0 & 28.3 \\
\hline & BHL Bilateral (16) & M (7) & 69.6 & 13.1 \\
\hline & & W (9) & 66.5 & 18.1 \\
\hline
\end{tabular}

are avoided and Accident/Incidents (Questions 11-15); and (C) Need for support systems or other requirements (Questions 16-20). In a pilot study, the questionnaire was tested on ten respondents, which led to slight modifications regarding instructions and clarity of questions. The project was approved by the regional ethics authority in Linköping.

With assistance from HRF, letters were sent out to members of the local branches. The letters included information about the purpose and aim of the study and an invitation to take part. Participants in the HL group were asked to sign and return an informed consent regarding the access of their audiogram. The control group was recruited through SPAR (the Swedish National Personal Directory). The participants were asked to $\log$ in to the web based questionnaire by a personal code enclosed with the information letter. A paper version was also supplied to those who replied that they did not use the Internet ( $n=6$ in the $\mathrm{NH}$ - group, $n=14$ in the HL group). Audiograms were provided by the local audiology clinic for the HL group.

\subsection{Analysis method}

Logistic regression was run with each question as dependent variable, binary for questions answered by "yes" or "no" (Questions 4, 11, 12, 17, 18, 20) and ordinal for questions answered with a point on a scale (Questions 5-10, 13-16). Gender, Bilateral or Unilateral and Hearing Category (HL0 HL4) were fixed factors, while Age was a continuous variable. All were entered simultaneously. For each dependent variable $\mathrm{NH}$ was first set as a reference among the hearing categories, and then the testing was repeated with each of the other four hearing categories (Mild HL, Moderate HL, Severe HL and Profound HL) as a reference. The results from the statistical analysis are presented with Odds Ratio $(O R)$. This gives a measure of the influence of the factor on the dependent variable. $O R=1$ means no influence, $O R>1$ means an increasing influence and $O R<1$ means a decreasing influence. For Age, being a continuous variable, OR is a measure of the influence per year. The confidence interval (CI) was $95 \%$ through the analysis, and thus all significances presented have $p<0,05$. Interaction effects between Hearing Category and Gender and between Hearing Category and Bilateral were tested, but no significant effects were found.

\section{Results}

The results are presented in three sections according to the major questions: how hearing loss affects the choice of transportation mode; view on hearing loss in relation to transport situations; and need and design of support systems for road users with hearing loss (see Appendix). In each section, there is a table presenting the significant 
differences, with $O R$ and limits for CI $95 \%$, that emerged from the analysis. Questions were no significant difference emerged are mentioned in text after the table.

\subsection{Choice of transportation mode}

The questions regarding choice of transportation (Questions 4-10) revealed that there was a relationship between the degrees of hearing loss and driving license, such that prevalence of driving license decreased with higher degree of hearing loss, see Table $2(n=312)$. For example, the probability of participants with mild hearing loss to have a driving license was higher than of participants with profound hearing loss $(\mathrm{OR}=9.42)$. However, this was not reflected in mileage per year, since Profound HL report more mileage per year than $\mathrm{NH}$ do. Additionally, for mileage driven last year, no effect of hearing category emerged. Hearing loss was not related to the frequency of transportation mode. A general pattern of result that emerged was that the use of all transportation modes decreased with increasing age. E.g. the probability of an individual older than another to ride a bike is smaller $(\mathrm{OR}=0.96$ per year older). Degree of hearing loss was related to criteria for choosing transportation mode and most apparent was that audible or written information was significantly more important for profound HL than for the other categories. Additionally, time was more important for Profound $\mathrm{HL}$ than for $\mathrm{NH}(\mathrm{OR}=4.14)$.

For comfort, mobility, feeling of security, cost and availability no significant effects were found for any of the factors. Analysis of choice of transportation in wintertime did not add any additional significant information.

\subsection{Hearing loss and transport situations}

Results from questions regarding hearing loss and transport situations (Questions 11-15) are presented in Table 3. The question of whether hearing loss effect driver abilities were answered only by respondents with driving license $(n=272)$. The ratings of avoidance of traffic environments and conditions are presented for car driving respondents only $(n=265)$. With a few exceptions, hearing loss did not affect the ratings of importance of hearing for different transportation modes. The exceptions were walking and public transportation, where hearing was rated as significantly more important for Moderate $\mathrm{HL}$ than for $\mathrm{NH}(\mathrm{OR}=3.04$ and $\mathrm{OR}=2.37$ respectively). A strong effect of gender emerged, such that women regard hearing capability as more important for all modes of transportation. Degree of hearing loss was related to several questions regarding driver abilities and the general pattern was that individuals with higher degree
Table 2 Frequency of transportation mode and criteria for choosing transportation mode. Hearing categories are according to Table 1. OR for age is per year

\begin{tabular}{|c|c|c|c|}
\hline $\begin{array}{l}\text { Dependent } \\
\text { variable }\end{array}$ & Significance for ratings & OR & CI $95 \%$ \\
\hline \multirow{6}{*}{$\begin{array}{l}\text { Driving license } \\
\text { (yes/no) }\end{array}$} & Higher for men & 5.77 & $2.45-13.6$ \\
\hline & Decrease with age & 0.96 & $0.94-0.99$ \\
\hline & Higher for NH than profound $\mathrm{HL}$ & 5.42 & $1.00-29.2$ \\
\hline & $\begin{array}{l}\text { Higher for mild HL than } \\
\text { profound HL }\end{array}$ & 9.42 & $2.11-42.0$ \\
\hline & $\begin{array}{l}\text { Higher for moderate HL than } \\
\text { profound HL }\end{array}$ & 6.45 & $1.86-22.4$ \\
\hline & $\begin{array}{l}\text { Higher for severe HL than } \\
\text { profound HL }\end{array}$ & 4.22 & $1.04-17.1$ \\
\hline \multirow{2}{*}{$\begin{array}{l}\text { Stopped driving } \\
\text { (yes/no) }\end{array}$} & Higher for men & 3.56 & $1.76-7.52$ \\
\hline & Increase with age & 1.08 & $1.04-1.11$ \\
\hline \multirow{4}{*}{$\begin{array}{l}\text { Mileage per } \\
\text { year }(\mathrm{km})\end{array}$} & Higher for men & 6.43 & $3.45-12.0$ \\
\hline & Decrease with age & 0.96 & $0.94-0.98$ \\
\hline & Higher for unilateral & 3.47 & $1.25-9.60$ \\
\hline & Higher for profound $\mathrm{HL}$ than $\mathrm{NH}$ & 6.49 & $1.07-42.5$ \\
\hline \multirow{3}{*}{$\begin{array}{l}\text { Mileage last } \\
\text { year }(\mathrm{km})\end{array}$} & Higher for men & 8.00 & $4.41-14.5$ \\
\hline & Decrease with age & 0.95 & $0.93-0.97$ \\
\hline & Higher for unilateral & 2.98 & $1.27-7.08$ \\
\hline \multirow[t]{2}{*}{ Car driver } & Higher for men & 6.22 & $3.89-9.95$ \\
\hline & Decrease with age & 0.93 & $0.91-0.95$ \\
\hline \multirow[t]{2}{*}{ Car passenger } & Higher for women & 2.61 & $1.68-4.05$ \\
\hline & Decrease with age & 0.98 & $0.96-0.99$ \\
\hline \multirow[t]{2}{*}{ Bike riding } & Higher for men & 2.08 & $1.21-3.57$ \\
\hline & Decrease with age & 0.96 & $0.94-0.98$ \\
\hline Moped driving & Decrease with age & 0.90 & $0.81-0.99$ \\
\hline Motorcycling & Decrease with age & 0.89 & $0.80-0.99$ \\
\hline Walking & Decrease with age & 0.96 & $0.95-0.98$ \\
\hline \multirow[t]{4}{*}{ Safety } & Higher for women & 1.53 & $1.04-2.43$ \\
\hline & Decrease with age & 0.97 & $0.95-0.98$ \\
\hline & $\begin{array}{l}\text { Higher for mild HL than } \\
\text { severe HL }\end{array}$ & 3.06 & $1.18-7.94$ \\
\hline & $\begin{array}{l}\text { Higher for mild HL than } \\
\text { profound HL }\end{array}$ & 3.37 & $1.02-11.0$ \\
\hline \multirow[t]{2}{*}{ Time } & Higher for $\mathrm{NH}$ than profound $\mathrm{HL}$ & 4.14 & $1.16-13.2$ \\
\hline & Decrease with age & 0.96 & $0.94-0.98$ \\
\hline Environm. issues & Higher for women & 1.57 & $1.03-2.40$ \\
\hline \multirow{5}{*}{$\begin{array}{l}\text { Audible or written } \\
\text { information }\end{array}$} & Increase with age & 1.03 & $1.01-1.58$ \\
\hline & Higher for profound $\mathrm{HL}$ than $\mathrm{NH}$ & 6.55 & $1.74-24.8$ \\
\hline & $\begin{array}{l}\text { Higher for profound HL than } \\
\text { mild HL }\end{array}$ & 5.75 & $1.66-19.9$ \\
\hline & $\begin{array}{l}\text { Higher for profound HL than } \\
\text { moderate HL }\end{array}$ & 4.14 & $1.28-13.4$ \\
\hline & $\begin{array}{l}\text { Higher for profound HL than } \\
\text { severe HL }\end{array}$ & 6.82 & $1.80-25.8$ \\
\hline
\end{tabular}

of hearing loss rated driver abilities less affected by hearing loss. E.g The effect on noticing risk situations was higher rated by Mild HL than by Profound HL $(\mathrm{OR}=4.39)$. Avoidance of specific traffic environments and 
Table 3 Importance of hearing, effect of hearing loss and avoidance of traffic environments. OR for age is per year

\begin{tabular}{|c|c|c|c|}
\hline Dependent variable & Significance for ratings & OR & CI $95 \%$ \\
\hline \multirow[t]{2}{*}{ Car driving } & Higher for women & 1.71 & $1.08-2.69$ \\
\hline & Increase with age & 1.03 & $1.00-1.04$ \\
\hline Bike riding & Higher for women & 2.46 & $1.44-4.20$ \\
\hline Moped riding & Higher for women & 2.03 & $1.30-3.18$ \\
\hline Motorcycling & Higher for women & 2.00 & $1.29-3.11$ \\
\hline \multirow[t]{2}{*}{ Walking } & Higher for women & 2.53 & $1.50-4.25$ \\
\hline & $\begin{array}{l}\text { Higher for moderate } \\
\text { HL than NH }\end{array}$ & 3.04 & $1.09-8.47$ \\
\hline \multirow[t]{2}{*}{ Public transportation } & Higher for women & 3.78 & $2.43-5.89$ \\
\hline & $\begin{array}{l}\text { Higher for moderate } \\
\text { HL than NH }\end{array}$ & 2.37 & $1.10-5.12$ \\
\hline $\begin{array}{l}\text { Communication with } \\
\text { other drivers }\end{array}$ & Increase with age & 1.04 & $1.02-1.05$ \\
\hline $\begin{array}{l}\text { Determination of car } \\
\text { function }\end{array}$ & Increase with age & 1.02 & $1.04-1.08$ \\
\hline \multirow[t]{3}{*}{$\begin{array}{l}\text { Determination of } \\
\text { road condition }\end{array}$} & $\begin{array}{l}\text { Higher for NH than } \\
\text { profound HL }\end{array}$ & 6.35 & $1.65-24.5$ \\
\hline & $\begin{array}{l}\text { Higher for mild HL than } \\
\text { profound HL }\end{array}$ & 5.31 & $1.57-18.0$ \\
\hline & $\begin{array}{l}\text { Higher for moderate HL } \\
\text { than for profound HL }\end{array}$ & 3.71 & $1.16-11.9$ \\
\hline \multirow[t]{2}{*}{ Paying attention } & Increase with age & 1.03 & $1.01-1.05$ \\
\hline & $\begin{array}{l}\text { Higher for NH than } \\
\text { severe HL }\end{array}$ & 2.56 & $1.16-6.49$ \\
\hline \multirow{2}{*}{$\begin{array}{l}\text { Noticing emergency } \\
\text { vehicles }\end{array}$} & Increase with age & 1.02 & $1.00-1.04$ \\
\hline & $\begin{array}{l}\text { Higher for NH than } \\
\text { severe HL }\end{array}$ & 3.00 & $1.08-8.25$ \\
\hline Using support systems & Not significant & & \\
\hline \multirow[t]{5}{*}{ Noticing risk situations } & Increase with age & 1.03 & $1.01-1.04$ \\
\hline & $\begin{array}{l}\text { Higher for NH than } \\
\text { severe HL }\end{array}$ & 3.00 & $1.16-7.77$ \\
\hline & $\begin{array}{l}\text { Higher for NH than } \\
\text { profound HL }\end{array}$ & 7.92 & $1.99-31.8$ \\
\hline & $\begin{array}{l}\text { Higher for mild HL than } \\
\text { profound HL }\end{array}$ & 4.39 & $1.25-15.2$ \\
\hline & $\begin{array}{l}\text { Higher for moderate } \\
\text { HL than profound HL }\end{array}$ & 4.05 & $1.23-9.87$ \\
\hline City traffic & Increase with age & 1.03 & $1.00-1.06$ \\
\hline \multirow[t]{2}{*}{ Darkness } & Increase with age & 1.05 & $1.03-1.07$ \\
\hline & Higher for women & 2.63 & $1.49-4.64$ \\
\hline \multirow[t]{2}{*}{ Slippery roads } & Increase with age & 1.04 & $1.02-1.07$ \\
\hline & Higher for women & 3.99 & $2.29-6.95$ \\
\hline \multirow[t]{2}{*}{ Fog } & Increase with age & 1.04 & $1.02-1.06$ \\
\hline & Higher for women & 4.14 & $2.37-7.23$ \\
\hline Complex crossings & Increase with age & 1.04 & $1.02-1.07$ \\
\hline Complex roundabouts & Increase with age & 1.04 & $1.02-1.07$ \\
\hline Unfamiliar roads & Increase with age & 1.05 & $1.02-1.07$ \\
\hline Driving with passengers & Increase with age & 1.03 & $1.00-1.06$ \\
\hline
\end{tabular}

conditions were mainly related to age. Avoidance was only related to hearing loss in a few specific situations, where again, the ratings were lower for Profound HL. Increasing age was associated with a general avoidance of most environments and conditions.

No significances were found for the ability of using support system, avoidance of driving on motorway or rural road or for driving without passenger. Additionally there was no significant effect of any factor on the involvement in incidents or accidents.

\subsection{Need and design of support systems}

Only active car driving respondents were included in the analysis of questions regarding need and design of support systems $(n=265)$. Table 4 displays the significant results for ratings of factors causing inattention during driving and attitudes towards warning system for driver inattention (Questions 16-20). The participants were asked to rate their general interest in warning systems and their attitudes towards specific warning modalities. Regarding the effect of hearing loss on factors causing driver inattention there was a single significance found, namely BHL rating talking on the phone as a higher cause of inattention $(\mathrm{OR}=2.57)$. For sleepiness, difficulty in finding the way, and type of distracting surrounding no significant difference was found. The general interest in a warning system for driver inattention was high among all respondents and the warning modalities that showed the most positive ratings included light, sound and seat vibration. There was an effect of hearing loss

Table 4 Factors causing inattention when driving and Interest in having a warning system for driver inattention. OR for age is per year

\begin{tabular}{llll}
\hline Dependent variable & Significance for ratings & OR & CI 95 \% \\
\hline Talking on the phone & Higher for women & 2.07 & $1.19-3.59$ \\
& Increase with age & 1.04 & $1.02-1.06$ \\
& Higher for Bilateral & 2.57 & $1.21-5.43$ \\
Writing text & Increase with age & 1.03 & $1.00-1.05$ \\
messages & Increase with age & 1.03 & $1.00-1.05$ \\
Passengers & Decrease with age & 0.97 & $0.94-0.99$ \\
General interest & Decrease with age & 0.98 & $0.96-1.00$ \\
Beep sound & Higher for NH than & 5.70 & $1.06-36.1$ \\
& profound HL & & \\
Flash light & Higher for bilateral & 2.47 & $1.01-6.17$ \\
Spoken voice & Decrease with age & 0.98 & $0.95-1.00$ \\
& higher for NH than mild HL & 3.28 & $1.03-10.5$ \\
& Higher for NH than & 3.57 & $1.01-12.9$ \\
& severe HL & & \\
& Higher for NH than & 10.9 & $1.06-99.1$ \\
profound HL & & \\
Decrease with age & 0.96 & $0.94-0.98$ \\
Steering wheel & Decrease with age & 0.96 & $0.94-0.99$ \\
vibration & Higher for profound HL & 4.66 & $2.15-55.7$ \\
& than moderate HL & & \\
\hline
\end{tabular}


on warning modalities, such that loss of hearing led to less interest in beep sound and spoken voice warning, while steering wheel vibration was significantly higher rated by Profound HL than by Moderate HL. Most respondents $(65 \%)$ thought that more auditory information could be useful and there were no significant effect of hearing category, age or gender.

\section{Discussion}

The present study was designed to examine three questions: (a) how hearing loss affects the choice of transportation mode; (b) view on hearing loss in relation to transport; and (c) need and design of support systems for road users with hearing loss. In general, the results reveal that hearing loss, affects some aspects regarding how individuals experience safety as well as mobility in transport situations, where as other situations remain unaffected by the degree of hearing loss.

\subsection{Choice of transportation mode}

A new finding is that prevalence of driving license had a strong negative correlation with degree of hearing loss. However, this was not reflected in mileage driven, which was not negatively affected by hearing loss. The implication is that respondents with driving license all drive to the same extent regardless of hearing loss or not. Mileage per year was significantly higher for Profound HL than for $\mathrm{NH}$, however in mileage last year, there was no difference found. This may imply that these individuals think that they drive more than they actually do, since mileage per year suggests an estimation and mileage last year is a more precise question. For respondents with Severe HL and Profound HL without driving license, the reasons for not having a driving license included other medical motives, such a vision disorder or a disability affecting the motoric performance.

When it comes to distribution of how much each mode of transportation was used, the typical pattern of men driving and women being passengers appeared. Also less transportation as function of increasing age was in line with previous research c.f. [3]. Degree of hearing loss did not affect the distribution of how often each mode of transportation was used, although there was a strong effect on the criteria for choosing transportation. This might be explained by several respondents having commented that each mode of transportation has its own specific problems. For ratings of criteria that are important when choosing transportation mode, in all significant differences found, either Severe HL or Profound HL were involved, indicating that loss of hearing affect choice of transportation, which is a new finding. This also indicates that there are other or additional criteria to consider due to the severe or profound hearing loss. Respondents with Mild HL rated safety higher than Severe HL do. This might imply that individuals with higher degree of hearing loss have to consider additional aspects. For example, time was not as important for Profound HL as for $\mathrm{NH}$, suggesting that a higher degree of hearing loss leads to other priorities than a fast transport. Furthermore, written information was more important for Profound HL than the other groups. This seems reasonable since the less you hear, the more you are in need of written information. Safety and environmental issues were higher rated by women than by men. This is in line with previous research c.f. [14], who revealed that safety skills increase as a function of femininity. This is a cultural and social concept related to gender, which is most commonly but not exclusively seen in women [6]. Increasing age led to lower priority of fast transportation and higher priority of audible or written information. These attitudes correspond with those in Profound HL which is not surprising since hearing loss increases with age.

\subsection{Hearing loss and transport situations}

There was only minor effect of hearing loss on the question of how important hearing is for different transportation modes, Moderate HL rated hearing as more important when walking and for public transportation than NH. Possibly, for individuals with normal hearing, it is difficult to imagine how audible information is needed in these situations. There was a strong effect of gender, such that women experience that hearing is more important for all modes of transportation, which corresponds with the women being more anxious and thinking more about safety c.f. [3]. In general, the effect of hearing on driver abilities was higher rated by $\mathrm{NH}$ and Mild HL than by Profound HL and in some cases also than by Severe HL, which is a new finding. One explanation could be that a higher degree of hearing loss forces the individuals to use different forms of coping strategies, which can be seen as a sort of adaptation. Tactical compensation (e.g. timing, distance, avoidance) is a known coping strategy among older drivers, proven to support mobility and reduce accident risk. By adopting slower speed and longer following distance, mental workload is reduced and attention allocated to process relevant information to the driving task [1]. For individuals with hearing loss, Andersson and Hägnebo [2] have shown that strategic problem solving and self-controlling coping strategies are more frequently used than escape or avoidance. This is in line with hearing loss having no effect on avoidance of any specific 
traffic situations or environments. A general feature of avoidance was correlated with age c.f. [3]. Women reported avoidance of more situations than men did c.f. $[3,9,11]$.

\subsection{Need and design of support systems}

There were no significant results for involvement in incidents or accidents. According to the literature, higher inattention [12] and poorer driving performance in the presence of distractors [5] is to be expected in older adults with hearing loss. This contradiction might be an indication of the fact that drivers with hearing loss have developed coping strategies to avoid distractors or to compensate for their hearing loss, or a combination of the both.

The general interest in a warning system for driver inattention was high regardless of hearing loss and the modalities with most positive ratings were (in descending order) light, sound, and vibration. This is not surprising since light and sound are those most commonly used in cars and thus more familiar to all drivers. That steering wheel vibration was significantly more interesting for individuals with profound hearing loss, than for individuals with moderate hearing loss, is probably a result of other modalities being less suitable. There was no significant difference for the question whether there are traffic situations where it could be useful to strengthen or complement auditory information. Among all respondents $65 \%$ thought that more auditory information could be useful.

\section{Conclusion}

Prevalence of driving license decreases with hearing loss, although mileage driven is not negatively affected. Hearing loss influences the criteria for choosing transportation mode, however has no effect on the distribution of how much each mode of transportation is used. In general, respondents with higher degree of hearing loss are less concerned, indicating that they might have developed coping strategies to handle their hearing loss. The interest in warning system for inattention is high regardless of hearing category. This yields also for the attitude towards strengthening of auditory information in traffic situations. Preferred warning modalities are (in descending order) light, sound and seat vibration. This suggests further research on coping strategies and on design of support systems accessible for drivers with hearing loss.

Acknowledgment We appreciate the support from HRF (Swedish Hard of Hearing Society) and from the Audiology clinics in Linköping and Norrköping.

Open Access This article is distributed under the terms of the Creative Commons Attribution License which permits any use, distribution and reproduction in any medium, provided the original author(s) and source are credited.

\section{Appendix}

\author{
1. Man $\square$ Woman $\square$ \\ 2. Date of birth? \\ 3. Do you have a loss of hearing? \\ If yes, what type of hearing loss? \\ 4. Do you have a driving license? \\ Year: \\ Yes $\square \quad$ No $\square$ \\ Yes $\square \quad$ No $\square$ \\ a) If yes, what year did you receive your driving license? \\ b) If no, why not? \\ 5. Approximately how many kilometers do you drive per year normally? \\ $\square 0 \quad \square 0-1000 \quad \square$ 1001-3000 $\square$ 3001-5000 $\square$ 5001-10000 $\square$ More than 10000
}

6. Approximately how many kilometers did you drive last year (2010)?

$\square 0 \quad \square 0-1000 \quad \square 1001-3000 \quad \square 3001-5000 \quad \square 5001-10000 \quad \square$ More than 10000

Comments:

7. What is your main occupation at the moment? (Tick only one alternative)

a) $\square$ Employed

b) $\square$ Self-employed

c) $\square$ Student

d) $\square$ Retired

e) $\square$ Sick listed (more than 3 months)

f) $\square$ On leave of absence

g) $\square$ Unemployed

h) $\square$ Homemaker

i) $\square$ Other, namely 
8. How often do you use the following modes of transportation in summertime?

$\begin{array}{cccccc}\text { Never } & 1-2 & 1-2 & 3-4 & 5-6 & \text { Daily } \\ & \text { times/ } & \text { times/ } & \text { times/ } & \text { times/ } & \\ \square & \text { month } & \text { week } & \text { week } & \text { week } & \\ \square & \square & \square & \square & \square & \square \\ \square & \square & \square & \square & \square & \square \\ \square & \square & \square & \square & \square & \square \\ \square & \square & \square & \square & \square & \square \\ \square & \square & \square & \square & \square & \square \\ \square & \square & \square & \square & \square & \square\end{array}$

Comments:

9. How often do you use the following modes of transportation in wintertime?

Car(as driver)

Car (as passenger)

Bicycle

Moped

Motorcycle

Public transportation (e.g.

bus or train)

Walking (at least $3 \mathrm{~km}$ )

$\begin{array}{cccccc}\text { Never } & 1-2 & 1-2 & 3-4 & 5-6 & \text { Daily } \\ & \text { times/ } & \text { times/ } & \text { times/ } \\ \text { month } & \text { week } & \text { week } & \text { week }\end{array}$

Car(as driver)

month week week week

Car (as passenger)

$\begin{array}{llllll}\square & \square & \square & \square & \square & \square \\ \square & \square & \square & \square & \square & \square \\ \square & \square & \square & \square & \square & \square \\ \square & \square & \square & \square & \square & \square \\ \square & \square & \square & \square & \square & \square \\ \square & \square & \square & \square & \square & \square\end{array}$

Bicycle

Moped

Motorcycle

Public transportation (e.g.

bus or train)

Walking (at least $3 \mathrm{~km}$ )

Comments:

10. On a scale from 1 to 5 , where 1 is Totally unimportant and 5 is Very important, how important are the following criteria for you when choosing transportation mode?

\begin{tabular}{lccccc} 
& $\begin{array}{c}1 \\
\text { Totally }\end{array}$ & 2 & 3 & 4 & 5 \\
unimportant & & & & $\begin{array}{c}\text { Very } \\
\text { important }\end{array}$ \\
Comfort & $\square$ & $\square$ & $\square$ & $\square$ & $\square$ \\
Mobility & $\square$ & $\square$ & $\square$ & $\square$ & $\square$ \\
Safety & $\square$ & $\square$ & $\square$ & $\square$ & $\square$ \\
Feeling of security & $\square$ & $\square$ & $\square$ & $\square$ & $\square$ \\
Cost & $\square$ & $\square$ & $\square$ & $\square$ & $\square$ \\
Time & $\square$ & $\square$ & $\square$ & $\square$ & $\square$ \\
Environmental issues & $\square$ & $\square$ & $\square$ & $\square$ & $\square$ \\
Availability & $\square$ & $\square$ & $\square$ & $\square$ & $\square$ \\
Audible or written information & $\square$ & $\square$ & $\square$ & $\square$ & $\square$ \\
Other, namely & $\square$ & $\square$ & $\square$ & $\square$ & $\square$ \\
\hline Comments: & & & & & $\square$
\end{tabular}

11. Have you as a driver experienced a serious incident during the last five years (20062010)? (By a serious incident a situation very close to result in an accident is meant.)

Yes $\square \quad$ No $\square$

If yes, how many times: times

Comment: 
12. Have you as a driver experienced a road accident during the last five years (20062010)? (By road accident a situation in road traffic, were at least one vehicle was in movement and a person was injured is meant.)

$$
\text { Yes } \square \quad \text { No } \square
$$

If yes, how many times: times

Comment:

13. On a scale from 1 to 5 , where 1 is Totally unimportant and 5 is Very important, how important is hearing as an information channel for the following Traficant groups?

$\begin{array}{lcccccc}\begin{array}{c}1 \\ \text { Totally } \\ \text { unimportant }\end{array} & 2 & 3 & 4 & \begin{array}{c}5 \\ \text { Very } \\ \text { important }\end{array} & \begin{array}{c}\text { Don't } \\ \text { know }\end{array} \\ \text { Car drivers } & \square & \square & \square & \square & \square & \square \\ \text { Bicyclists } & \square & \square & \square & \square & \square & \square \\ \text { Moped rider } & \square & \square & \square & \square & \square & \square \\ \text { Motorcyclists } & \square & \square & \square & \square & \square & \square \\ \text { Pedestrians } & \square & \square & \square & \square & \square & \square \\ \text { Travelers in public } & \square & \square & \square & \square & \square & \square \\ \text { transportation } & \square & \square & & & \square\end{array}$

Comments:

14. On a scale from 1 to 5 where 1 is Not at all and 5 is Very much, to what extent do you think that reduced hearing affect the drivers ability to:

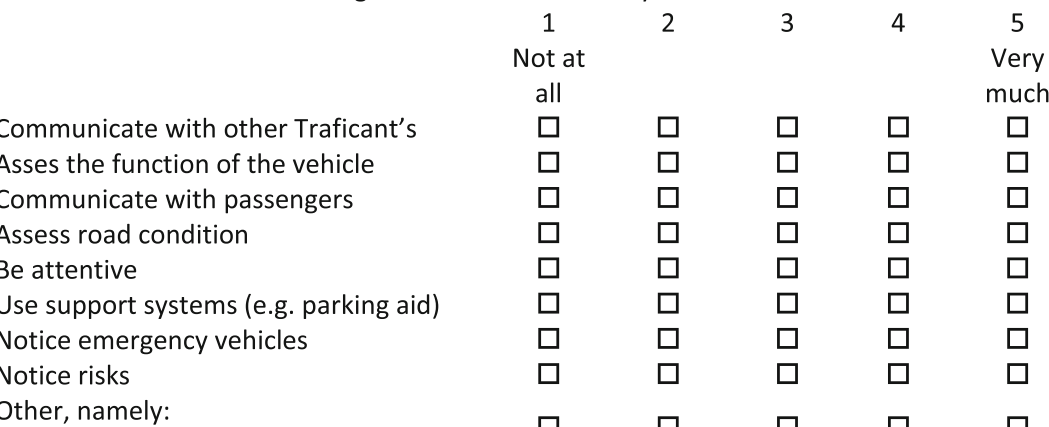
Other, namely:

Comments:

15. On a scale from 1 to 5 where 1 is Never and 5 is Always, How often do you deliberately avoid car driving during the following conditions or in the following traffic environments?

Motorway

Rural road

City traffic

Driving in the dark

Slippery roads

Driving in fog

Complex crossings

Complex roundabouts

Unknown roads

With passenger

Without passenger

Other, namely:

$\begin{array}{cccccc}1 & 2 & 3 & 4 & 5 & \text { Not } \\ \text { Never } & & & & \text { Always } & \text { relevant } \\ \square & \square & \square & \square & \square & \square \\ \square & \square & \square & \square & \square & \square \\ \square & \square & \square & \square & \square & \square \\ \square & \square & \square & \square & \square & \square \\ \square & \square & \square & \square & \square & \square \\ \square & \square & \square & \square & \square & \square \\ \square & \square & \square & \square & \square & \square \\ \square & \square & \square & \square & \square & \square \\ \square & \square & \square & \square & \square & \square \\ \square & \square & \square & \square & \square & \square \\ \square & \square & \square & \square & \square & \square \\ \square & \square & \square & \square & \square & \square\end{array}$

Comments: 
16. To what extent do the following factors make you inattentive when driving?

Sleepiness

Talking on the phone

Reading or writing text messages

Adult passengers (over 16 years)

Children passengers (6-16 years)

Children passengers ( $0-5$ years)

Difficulty in finding the way

Beautiful surroundings

Boring surroundings

Commercial/ shops

Other, namely:

\begin{tabular}{|c|c|c|c|c|c|}
\hline 1 & 2 & 3 & 4 & 5 & Not \\
\hline $\begin{array}{c}\text { Not at } \\
\text { all }\end{array}$ & & & & $\begin{array}{l}\text { Very } \\
\text { much }\end{array}$ & relevan \\
\hline$\square$ & $\square$ & $\square$ & $\square$ & $\square$ & $\square$ \\
\hline$\square$ & $\square$ & $\square$ & $\square$ & $\square$ & $\square$ \\
\hline$\square$ & $\square$ & $\square$ & $\square$ & $\square$ & $\square$ \\
\hline$\square$ & $\square$ & $\square$ & $\square$ & $\square$ & $\square$ \\
\hline$\square$ & $\square$ & $\square$ & $\square$ & $\square$ & $\square$ \\
\hline$\square$ & $\square$ & $\square$ & $\square$ & $\square$ & $\square$ \\
\hline$\square$ & $\square$ & $\square$ & $\square$ & $\square$ & $\square$ \\
\hline$\square$ & $\square$ & $\square$ & $\square$ & $\square$ & $\square$ \\
\hline$\square$ & $\square$ & $\square$ & $\square$ & $\square$ & $\square$ \\
\hline$\square$ & $\square$ & $\square$ & $\square$ & $\square$ & $\square$ \\
\hline$\square$ & $\square$ & $\square$ & $\square$ & $\square$ & $\square$ \\
\hline
\end{tabular}

Comments:

17. A distraction warning system warns a driver who has been distracted from the driving task. The purpose of the system is to make the driver attentive to the driving task. Would you be interested in having that system in your car?

Yes $\square \quad$ No $\square \quad$ Not relevant $\square$

18. If you would have a distraction warning system in your car, how would you like to receive the warning? (You can tick several boxes)

Yes No Don't

By a sound(e.g. a beep)

know

By a light

$\square \quad \square \quad \square$

By a voice

By a seat vibration

By a belt vibration

$\square \quad \square \quad \square$

Other, namely:

Comments:

19. Can you in your own words describe traffic situations where hearing impression can play an important role?

20. In your opinion, are there traffic situations where it could be useful to strengthen hearing impressions and/or give complementing information?

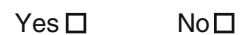

If yes, what kind of information? Describe what you think: 


\section{References}

1. Adrian J, Postal V, Moessinger M, Charles A (2010) Implication of the cognitive functions and personality traits on tactical compensation among older drivers: A gender comparison. Paper presented at the 12th International Conference on Mobility and Transport for Elderly and Disabled persons (TRANSED 2010) held in Hong Kong on 2-4 June 2010

2. Andersson G, Hägnebo C (2003) Hearing impairment, coping strategies and anxiety sensitivity. J Clin Psychol Med S 10(1):35-39

3. Dillén J, Schmidt L, Jarlebring I (2005) Äldre personers resvanor och aktiviteter/Older adults travel habits and activities. Solna: Transek:23. Available at: http://www20.vv.se/fud-resultat/Publikationer_000301 000400/Publikation_000316/\%C3\%841dre\%20rapport\% 20051020\%20FINAL.pdf. Accessed Jan 24, 2012

4. Englund L (2001) Medicinska förhållanden av betydelse för innehav av körkort - Hörsel och balanssinne. Medical conditions of importance for driving license-Hearing and balance. In: Almgren M (ed) Trafikmedicin. Vägverket, Trafikmedicinska rådet, Borlänge

5. Hickson L, Wood J, Chaparro A, Lacherez P, Marszalek R (2010) Hearing impairment affects older people's ability to drive in the presence of distracters. J Am Geriatr Soc 58(6):1097-1103

6. Hirdman Y (2003) Genus: Om det stabilas föränderliga former / Gender: about the inconstancy of the stable. Liber, Malmö

7. Hjorthol R, Levin L, Sirén A (2010) Mobility in different generations of older persons: the development of daily travel in different cohorts in Denmark, Norway and Sweden. J Transp Geogr 18(5):624-633
8. HRF, Hörselskadades riksförbund, The Swedish Hard of Hearing Society (2009) HRF Rapport, HRF Report. Stockholm. Available at: http://www.hrf.se/upload/pdf/rapport09.pdf. Accessed Jan 24, 2012

9. Levin L, Dukic T, Heikkinen L, Henriksson P, Linder A, Mårdh S, Nielsen B, Nygårdhs S, Peters B (2007) Äldre i transportsystemet Mobilitet, design och träningsproblematik. The elderly in the transport system - mobility, design and training problems: VTI report; (R593). Available at: http://www.vti.se/sv/publikationer/ aldre-i-transportsystemet-mobilitet-design-och-traningsproblematik. Accessed Jan 24, 2012

10. Lundälv J (2004) Self-reported experiences of incidents and injury events in traffic among hearing impaired people as pedestrians and cyclists. A follow-up study of mobility and use of hearing equipment. Int J Rehabil Res 27(1):79-80

11. Rosenbloom S (1956) Is the driving experience of older women changing? Safety and mobility consequences over time. Transp Res Rec 2006:127-132

12. Schmolz W (1987) Die Bedeutung des Hoehrens im Verkehr. The importance of hearing in traffic. Polizei Verkehr Technik 32 (11):379-380

13. Türker Ö, Lajunen $\mathrm{T}$ (2006) What causes the differences in driving between young men and women? The effects of gender roles and sex on young drivers' driving behaviour and self-assessment of skills. Transp Res F 9:269-277

14. WHO (1991) Report from informal working group on prevention of deafness and hearing impairment programme planning: WHO, Geneve 